\title{
Competence and Knowledge at Work
}

\begin{abstract}
The theme of this book is long career competence in the workplace and competence of course includes a range of skills, ability and knowledge, which makes it possible for the individual to function and contribute in the workplace. What is considered appropriate competence will vary in different organisations and be dependent on the work, profession or tasks an employee is expected to carry out. The close link between competence and work means that it is not enough to simply know something; one must know how to carry out a task. There are many theories of knowledge and how competence is developed and used; here we focus on how competence and work-related knowledge have been conceptualised and how they have been used in relation to older employees. We include organisational knowledge, situated knowledge, professional knowledge and expertise and discuss how these concepts might be useful in understanding late career competence and older employees.
\end{abstract}

Keywords Organisational knowledge - Situated knowledge - Expertise · Professional knowledge · Competence . Older workers 


\subsection{Organisational KnOWLEdge}

A great deal of research on knowledge in work situations has been carried out by management scientists or economists with a desire to understand the value of organisations and how their human capital can be optimised. Different terms have evolved to describe knowledge such as tacit, explicit, procedural, dispersed or embedded, to name but a few. Knowledge is usually viewed as something owned by the organisation and something which has a value for the organisation. While researching this chapter we carried out searches of online databases for publications on organisational knowledge and learning. We found a large number of publications in the period up until 2005, however after that date there was a reduction in the number of publications on these themes and few notable attempts to develop theories which might be relevant for the age group in our studies. Some of the themes we found were related to knowledge sharing, knowledge networks and intra-professional knowledge as well themes related to culture and gender. We found that the more general findings on organisational knowledge and learning in the pre-2005 publications have frequently been incorporated into services provided by business consultants supporting HR and training managers. This suggests that many of the earlier findings have been accepted and we would expect to find them incorporated in working practice. We therefore chose to focus on the more classical works on organisational knowledge and use these studies to guide our work.

Metcalfe and Gibbons (1989) use the term knowledge base and they suggest that the knowledge base of an organisation is what defines the organisation. The way an organisation develops or acquires new knowledge, the way they articulate and enhance their knowledge is what gives the organisation its uniqueness and usually its competitive advantage. The idea of an organisation having a knowledge base is further developed by economists studying innovation such as Tidd et al. (2005) who describe the importance of "firm specific competences". The research done by Tidd et al. is based mainly on firms developing new technologies and they provide examples of firms developing theoretical knowledge based on their research and development work and developing practical knowledge from building and developing these technologies. Leonard (1998) discusses the development of firm-specific capabilities and the mechanisms which promote or hinder knowledge sharing and co-creation. Her theories have a lot in common with the concept of "core competencies" 
which was introduced by Prahalad and Hamel (1990), who describe these competencies as being the "collective learning of the organisation" and again highlight the importance of this knowledge in defining the position of the organisation in relation to competitors.

Other studies have developed the theme of organisational knowledge focusing on specific aspects. An example of this is the work focused more on knowing, rather than knowledge (Antonacopoulou, 2006). She attempts to avoid the limitations of viewing knowledge as an object separate from the context and processes which produced it. She proposes seven forms of knowing which are based on learning as problem-solving or "learning as a mystery". She distinguishes between hard technical knowledge and soft management knowledge and concludes with the following categories:

- Knowing by storing-when the emphasis is collecting relevant knowledge for a specific task.

- Knowing by repeating-when the emphasis is applying specific knowledge to similar situations.

- Knowing by improvising - when the emphasis is on exploring ways in which knowledge may be utilised in unfamiliar situations.

- Knowing by reflecting - when the emphasis is on the search for new meaning in relation to what is currently known.

- Knowing by questioning-when the emphasis is on assessing the relevance and applicability of knowledge in new situations and accepting ignorance.

- Knowing by synthesising - when the emphasis is on integrating what is known with what is discovered.

- Knowing by transforming-when the emphasis is on searching for a new platform of understanding.

\section{(Ibid.: 26)}

This way of focusing on knowing, rather than knowledge is interesting in terms of the current study of older employees particularly because it provides us with new ways of identifying learning based on the activities or ways of working described by workers themselves. This makes it possible to identify examples of learning which the learner may not be aware of.

Another thread of research which built on some of the ideas on organisational knowledge was the work of Lundvall and others who were 
interested in innovation and development of the knowledge economy. Lundvall was interested in how organisations use their knowledge to create economic growth. Lundvall was particularly interested in tacit knowledge and how firms and nation states could stimulate its development and then use it to create new products and services. Building on the studies of Ryles (1949), Lundvall developed a model of four knowledge types and a way of viewing the activities which are a prerequisite to developing these knowledge types.

- Know what

- Know why

- Know how

- Know who

(Lundvall, 1996: 5)

Know-what is based on learning facts, while know-why knowledge is an understanding of, for example, the laws of nature. Both these kinds of knowledge typically arise while undergoing formal education and the know-why kind of knowledge is predictably greater among those with a longer formal education. The know-how knowledge is usually based on practical experience, this kind of knowledge may be unique to the individual, but we would also expect to find it among groups of employees engaged in similar same activities, or those who have worked together in a project. The know-who kind of knowledge was the Lundvall's addition to earlier models and was the one that he viewed as being most important for innovation. Knowing who might know something which you don't know, knowing who has already done the task you are trying to do, knowing who has spoken or thought about the challenges you face. In all these examples the knowledge necessary to proceed can be gained in other ways than knowing who, however as Lundvall points out, knowing who and going directly to them is much faster. Lundvall sees this kind of knowledge as an integral part of working and existing in a modern technology-driven world.

Know-who and know-how are viewed as challenging for management as the skills necessary to know-who, to interact socially and absorb, share and embed new knowledge are not things which can be learned by going on a course. We understand a lot about practice-based knowledge, or know-how, however much of this knowledge is tacit and much of it arises 
when the learner is doing something else, i.e. not consciously learning. Therefore, neither employees nor employers may be aware of this kind of knowledge until the employee leaves and a gap suddenly appears. Not only are know-who and know-how challenging for management, but Lundvall also suggests that this kind of knowledge is dependent upon trust and requires, not only a network of useful contacts, but also the social skills to create and develop social networks. The concepts of knowwho and know-how are particularly interesting with regard to the current study of older workers because both concepts implicitly assume a certain kind of pre-knowledge or experience that has been developed over time.

\subsection{Situated KnOWledge}

While economists and management scientists were developing their own interpretations of organisational knowledge, studies of science and technology (STS) and feminist studies were developing some related concepts, one of these is situated knowledge. The concept of situated knowledge challenges the belief that there is any can kind of knowledge other than knowledge developed in situ and this of course challenges the value, or indeed the existence of knowledge derived from academic studies. Social studies of science and technology have questioned the objectivity of scientific knowledge and how we can understand objective knowledge without also accepting subjective interpretations.

Donna Harroway, a feminist researcher, was one of the first to draw attention to situated knowledge and it was in an attempt to provide a theory of objectivity (Thompson, 2015). Haroway (1998) wanted to step away from the traditional idea of knowledge as something separate from learning, to step away from the traditional idea of teacher and learner in a one-way dialogue and wanted instead to include learners, teachers or colleagues in an ongoing situation of knowledge production. As Thomson points out, it is common to view knowledge, at least scientific knowledge, as something universal no matter who possesses it, rather than something which has its real value in the situation where it was produced. Both Thomson and Harroway agree that scientific knowledge or impartial knowledge is dependent on the partiality of the local situation with its unique combination of persons and objects. This is also a theme developed by Knorr-Cetina (2003 [1999]). 
An interesting aspect of situated learning is the concept of learning trajectories which stretch across space and time. In their analysis of situated learning, Lave and Wenger (1991) stress the importance of the gradual development of skills over time. They mention the learning opportunities provided by "the ongoing flow of reflective moments" (ibid.: 54) and how a variety of trajectories expose workers to different forms of participation in their tasks and transform them in different and unpredictable ways (ibid.: 19).

The concept of situated knowledge can be challenging for researchers studying older employees, because the concept does not deal with what happened before the situation in the same way as other concepts of knowledge. When discussing progression from newcomer to old-timer, the concept of situated knowledge emphasises the gradual development of identity rather than how the employee accesses a source of prior knowledge. Lave and Wenger (1991) describe this as moving from the periphery into the centre in terms of their trade. So, years spent on perfecting skills and performing tasks at work is a prerequisite to becoming an old-timer or a master craftsman, but there is less emphasis on the importance of formal or explicit knowledge. We might expect our older employees in the current study, to be masters of their roles at work, to be in the centre of their field. In terms of situated knowledge, we would expect that older employees would be understanding and interpreting their situation based on their own experiences either with the same employer or with multiple employers. We would expect older employees to have different views and understanding of historical events, of job descriptions, of formal procedures, of decisions taken, of strategies and of organisational changes depending on the situation now and the situation in the past. It is not certain that these understandings and interpretations will differ radically from those of younger employees, indeed the differences might not be identified by researchers who do not get an in-depth understanding of the situation and the interviewee's interpretations of it. By asking older employees to share their experiences of situations and how they reacted to them, we can gain useful information about what they bring to these situations in terms of experience and what they learn from these situations. 


\subsection{Expertise and Professional Knowledge}

Many years of research have been devoted to the theme of expertise and how experts or professionals work. Here we consider the findings of some of these researchers, such as, Collins and Evans, Eraut and the Dreyfus brothers. Since professional status and expertise require an extended period of time to develop and master, we thought that these concepts might be relevant to our understanding of older workers and their competence.

As with the other studies reviewed in this chapter, it is often difficult to separate concepts of knowledge or competence from the process of developing this knowledge or competence. Dreyfus and Dreyfus (1986) is an example of this. They developed a model of skills acquisition which describes the stepwise changes a novice must progress through to become an expert. The model consists of five discrete steps from novice, through advanced beginner, competent and proficient to expert. One of the main features of the model of skills acquisition is that the learner begins by learning the facts and carefully following the rules, as the novice progresses, more activities are carried out in a swift, intuitive way. While this model might well work when explaining how one learns to dance a tango, it has been criticised because of its limitations. One of the limitations is the kind the problem the employee is dealing with, if it is a simple problem, such as should I change gear in the car?, then we do see that experienced drivers act in an swift and intuitive way, however if you are trying to communicate new laws or regulations and their consequences for employers, then you require more than a swift intuitive answer. One must be able to interpret the listener, has he or she understood? Then consider rephrasing the information and communicating it in a new way. This is only one example, but it suggests that when the issue is more complex and cannot simply be memorised, that it will require a combination of intuition and conscious evaluation. For example, the delicate balance between tacit and explicit knowledge necessary for a medical practitioner to make a diagnosis does not fit easily into the model. The increasing importance of tacit knowledge and intuitive nature of the actions of many experts makes this model interesting, however there is more to senior competence than simply tacit knowledge and intuition.

Collins and Evans (2009) have observed a change in the way in which expertise has been understood, "a move away from seeing knowledge 
and ability as quasi logical or mathematical and toward a more wisdombased or competence-based model" (ibid.: 23). In their periodic table of expertise Collins and Evans (ibid.: 14) present a matrix of knowledge associated with experts and non-experts. This model is quite complex with different levels and many sub-divisions, here we mention the most important types of knowledge and competence, thereafter we select the subcategories which might be affected by age or by having a long working career.

Collins and Evans distinguish between a knowledge of facts, which can be taught and learned, like how to move the bishop on a chess board and specialist tacit knowledge, which can only be gained by immersion in a field over a longer period of time. This tacit knowledge is further defined as including contributory expertise "which is what you need to do an activity with competence" (ibid.: 14) or internalised physical skills. The stages for developing this kind of skill, are similar to the model developed by Dreyfus and Dreyfus. The other kind of tacit knowledge which we would expect experts to exhibit is interactional knowledge which is "the ability to master the language of a specialist domain" (ibid.). Collins and Evans are particularly interested in this kind of expertise, because they claim that it has largely been ignored by academics and the focus has traditionally been on tacit or explicit knowledge. They describe interactional knowledge as more informal, than formal, however they suggest that this kind of knowledge can be developed without the expert having practice-based experience. It can be developed through dialogue with experts. They mention how journalists develop this kind of knowledge, or academics writing reviews on the work of others, also salespersons and managers typically develop interactional knowledge.

Collins and Evans point out that long experience alone is not equivalent to developing expertise, so we cannot assume that our older employees will all be more knowledgeable than their younger colleagues by sheer dint of being their longer. Experts are people who have used their long careers to develop skills. We may however expect some of our senior employees to have developed their skills in such a way that they have a high level of contributory knowledge or that they have mastered the language of their domain or have developed their interactional knowledge.

Professionals are often defined as a group of particular interest with regard to their competence and how it is developed. Most professions have their own formal education and training and indeed the body of 
theoretical knowledge linked to the profession is often central to the very existence of the profession itself. In his studies on developing professional knowledge, Eraut $(1994,2000)$ confirms the importance of formal education and training and mentions the importance of an understanding of shared knowledge, approved by the profession. However, in addition to all the formal training and understanding of theoretical knowledge, many professionals must also learn from practical experience. He points out the importance of prior examples of similar situations and how these experiences are regularly used to take decisions. Although many of the examples a professional will call upon will be from the professionals' own experience, much will also be learned from the reported experiences of others. The latter may be learned in a formal situation, such as lawyers and doctors studying documentation of previous cases, or they may be learned informally by exchanging experiences with colleagues (Eraut, 1994: 46). By learning from past experiences, it is possible for the expert to refine his or her understanding of which procedures and actions from previous examples will be most appropriate in the current situation. Eraut (ibid.) suggests that a semi-conscious patterning may take place, which makes it difficult for the professional to recognise or at least articulate the pattern which is being used. Learning from experience, is not simply living through the experience, but could occur when one consciously reflects upon an action. Focusing on an experienced action many times, as this action is repeated during a professional career, might result in a range of different meanings being generated from this action depending on the meaning, context and the moment (ibid.: 104). Much of what is learned from experience will not be the result of conscious learning, but might happen while the professional is doing something else and when learning is the last thing on her mind. Again this kind of learning is not something which can be completed during the first year of practicing a profession and suggests implicitly that older professionals and younger professionals may have very different competence and while both groups may have a similar relationship to theoretical knowledge, their relationship to practical knowledge will be different.

When analysed more closely, Eraut (2000) suggests that professional knowledge consists of:

- A combination of routine procedures

- Proficiency in these routines

- Ability to handle non-routine situations 
The ability to solve well-defined and ill-defined problems and to continuously develop new problem-solving strategies is important in order to be able to be an expert in one's profession. As Eraut points out, most professions consider the amateur as a person who tries to apply tried and tested solutions without engaging in the problem at hand and considering if there are perhaps multiple solutions to the problem and selecting the most appropriate. Problem-solving is addressed in formal professional training, however solving problems which are not easily described is usually learned from practical experience and therefore the expert is expected to have worked long enough in order to gain the experience necessary to develop these skills. As well as problem-solving skills, Eraut (ibid.) mentions communication, ability to work in teams and an understanding of ethics in practice as examples of competence which is important to most professions and which is not routinely taught in formal education or training courses.

\subsection{Competence, Knowledge and Seniors}

In this chapter we have presented some of the more traditional theories of organisational knowledge and learning at work. There is of course a large body of literature on career development at work. Much of the research on career development is indeed relevant in the context of lifelong learning; however, we have not included this literature. Questions about career development did not arise in our interactions with older employees although they did mention job mobility, which we will discuss later.

This brief overview of how knowledge at work has been conceptualised gives us an interesting starting point for understanding the kind of knowledge or competence which older employees might be talking about when we interview them. It also gives us an idea of the importance which different actors have attributed to different kinds of work-based knowledge. It is evident from these studies that the theme of age is not considered relevant in many of the better-known concepts of knowledge, however there is an underlying assumption of experience. This experience does not simply arise from elapsed time, but from time spent on a variety of tasks and overcoming challenges. Some of the concepts of knowledge discussed here and the methods used to identify knowledge and learning have helped us to formulate some of our interview questions and to interpret and understand our findings. We did however also 
want to consider research aimed more specifically at understanding age and older employees and this is described in the next chapter.

\section{RefERENCES}

Antonacopoulou, E. (2006). Modes of knowing in practice: The relationship between knowledge and learning revisited. In B. Renzl, K. Matzler, \& H. Hinterhuber (Eds.), The future of knowledge management.

Collins, H., \& Evans, R. (2009). Re-thinking expertise. The University of Chicago Press.

Dreyfus, H. L., \& Dreyfus, S. E. (1986). Mind over machine: The power of human intuition and expertise in the era of the computer. Basil Blackwell.

Eraut, M. (1994). Developing professional knowledge and competence.

Eraut, M. (2000). Non-formal learning and professional knowledge at work. British Journal of Educational Psychology, 70(1), 113-136.

Haroway, D. (1998). Situated knowledges: The science question in feminism and the privilege of partial perspectivce. Feminist studies, 14(3), 575-599.

Knorr-Cetina, K. (2003 [1999]). Epistemic cultures: How the sciences make knowledge. Harvard University Press. (Third printing 2003).

Lave, J., \& Wenger, E. (1991). Situated learning legitmate peripheral participation. Cambridge University Press.

Leonard, D. (1998). Wellsprings of knowledge. Harvard Business School Press.

Lundvall, B. A. (1996). The social dimension of the learning economy (DRUID Working Papers 96-1). DRUID, Copenhagen Business School, Department of Industrial Economics and Strategy/Aalborg University, Department of Business Studies.

Metcalfe, G. S., \& Gibbons, M. (1989). Technology, variety and organisation: A systematic perspective on the competitive process. Research on Technological Innovation Management and Policy, 4, 153-193.

Prahalad, C. K., \& Hamel, G. (1990, May-June). The core competence of the corporation. Harvard Business Review, pp. 79-90.

Ryles, G. (1949). The concept of Mind. Penguin.

Thompson, C. M. (2015). Situated knowledge, feminist and science and technology studies perspectives. International Encyclopedia of the Social and Behavioral Sciences, 22, 1-4.

Tidd, J., Bessant, J., \& Pavitt, K. (2005). Managing innovation (3rd ed.). Wiley. 
Open Access This chapter is licensed under the terms of the Creative Commons Attribution 4.0 International License (http://creativecommons.org/licenses/ by $/ 4.0 /$ ), which permits use, sharing, adaptation, distribution and reproduction in any medium or format, as long as you give appropriate credit to the original author(s) and the source, provide a link to the Creative Commons license and indicate if changes were made.

The images or other third party material in this chapter are included in the chapter's Creative Commons license, unless indicated otherwise in a credit line to the material. If material is not included in the chapter's Creative Commons license and your intended use is not permitted by statutory regulation or exceeds the permitted use, you will need to obtain permission directly from the copyright holder.

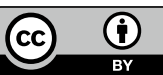

